\title{
A HISTÓRIA DE UMA INFANTICIDA
}

\section{THE HISTORY OF A CHILD MURDERER}

\author{
Sabrina Fernandes Melo*
}

PROSPERI, Adriano. Dar a alma: história de um infanticídio. São Paulo: Companhia das Letras, 2010. 505 p.

Em "Dar a alma: história de um infanticídio", primeiro livro de Adriano Prosperi e publicado no Brasil em 2010 pela Companhia das Letras, o autor parte de uma história particular, do caso "excepcional-normal” da jovem italiana Lucia Cremonini que mata seu filho logo após o nascimento. Lucia era uma moça pobre e solteira que vivia com sua mãe - viúva - em um pequeno quarto na cidade de Bolonha durante o século XVIII. Esse era o típico retrato da mulher com potencial infanticida: pobre, jovem, solteira, geralmente sem a proteção de uma figura masculina, seja um padre, marido, ou pai.

Prosperi parte especificamente do caso de Lucia - que, segundo ele, não se destoa de muitos outros casos de infanticídio registrados na Itália durante esse período - para abordar questões estruturais, sociais, culturais, jurídicas, teológicas e religiosas sobre o infanticídio, o aborto e a discussão em torno da alma e do batismo, culminando em um estudo que ultrapassa as fronteiras da Itália do século XVIII e perpassa por uma ampla discussão sobre questões filosóficas que permearam o mundo ocidental durante vários séculos.

O autor aborda o caso de Lucia fragmentariamente, pois busca elucidar o contexto do episódio do infanticídio descrito no processo policial em seus mais diferentes aspectos. Aspectos que vão desde a questão religiosa até a análise de cada personagem envolvido direta ou indiretamente no caso. Ele se esforça na tentativa de contextualizar e lançar luzes ao caso de Lucia, que não poderia ser entendido somente com a leitura e análise de seu processo pois

\footnotetext{
* Mestranda no Programa de Pós-Graduação em História na Universidade Federal de Santa Catarina (UFSC) e bolsista CAPES. E-mail: sabrina.fmelo@gmail.com
} 
seria um limitante para sustentar os argumentos e as propostas metodológicas e de pesquisa apresentadas no livro. Os diversos contextos em diferentes espaços de tempo traçados por Prosperi são utilizados para dar sentido, para se compreender o caso de Lucia Cremonini.

A primeira parte do livro verifica como o caso de Lucia foi parar nas mãos da justiça e faz uma descrição dos detalhes contidos nos autos. Lucia foi denunciada, pois após dar a luz a um menino mata-o, perfurando a garganta dele com uma faca. Ao chegarem ao local do crime, depois de uma denúncia, as autoridades se depararam com todas as provas necessárias para a criminalização de Lucia. O corpo do recém-nascido se encontrava no chão em uma sacola, a faca suja de sangue estava jogada em um canto do quarto e a acusada se encontrava deitada.

Em um primeiro momento, Lucia tenta negar o crime, alegando que após o parto a "criatura" - assim é tratado o recém-nascido, em diversas passagens dos autos, por não haver recebido um nome e muito menos batismo - havia caído no chão, pois ele também apresentava um ferimento no canto da boca. Após a verificação das provas, Lucia não teve como negar e acabou assumindo que matara seu filho e depois o jogara de cabeça para baixo na lareira. Na queda residia a explicação para o ferimento na boca da "criatura". Nesse período, mesmo estando óbvias todas as provas contra a acusada, a confissão era de suma importância para a conclusão do processo.

Nesse primeiro momento do livro, Prosperi levanta questões que ultrapassam as informações contidas no processo, pois ele se questiona sobre os motivos que levaram Lucia a cometer o infanticídio e sobre a identidade de Lucia: quem era afinal aquela mulher? O que ela sentia? Questões que são elucidadas a partir de outros documentos e da mescla de diferentes contextos para o preenchimento dessas lacunas.

$\mathrm{O}$ autor inicia a discussão acerca do infanticídio enquanto crime com inúmeros questionamentos tais como: quando começaram as penas jurídicas e religiosas? Qual era o pecado contido no ato do infanticídio? Nos tempos de Lucia, o infanticídio era definido geralmente pelo assassinato dos filhos cometidos pelos pais, porém essa concepção vai se estreitando e na linguagem criminalista daquele período, o termo infanticídio se aplicava quase exclusivamente à morte de um recém-nascido causada pela mãe.

Prosperi aborda a questão do infanticídio como obsessão do grande imaginário que circundava os assuntos relacionados à morte de um recémnascido. Muitos infanticídios eram considerados como uma prática comum a grupos e seitas - judeus, hereges, bruxas - responsáveis por rituais a partir do corpo e da morte de uma criança. A figura da bruxa (sempre associada à parteira) foi fundamental para a criação do imaginário de que as crianças 
recém-nascidas e principalmente aquelas não batizadas e, consequentemente, sem alma fossem usadas em rituais de magia.

Na segunda parte do livro Prosperi aborda e caracteriza a personagem presente nos autos, além de outras questões relacionadas à importância cultural e institucional da Igreja. A primeira personagem a ser analisada é Lucia. Esta, em seu primeiro depoimento declara ser uma moça honrada. A questão da honra é uma das peças chaves para se entender todo o desfecho do caso e também a questão da prática e criminalização do infanticídio. A honra era tão importante que o advogado de defesa de Lucia chama seus antigos patrões para deporem, os mesmos afirmaram que a jovem era honesta e digna, o padre de sua comunidade também depôs a favor da jovem. Muitas mulheres que cometiam infanticídio estavam preocupadas em manter sua honra, no sentido de castidade, visto que era o bem mais precioso que uma mulher poderia ter. Outrora, Se uma mulher ficasse grávida, fosse através de um ato de violência ou não, ou seja, fora de seu casamento, ela ficaria marcada na sociedade e seria de certa forma excluída, restando a ela, em muitos casos, a prostituição. Isso provavelmente aconteceria com Lucia, caso ela não tivesse matado seu filho.

Lucia declarou que fora deflorada por um jovem padre durante o carnaval e que jamais o tornou a ver. O padre consta nos autos do processo como uma figura enigmática, não se sabe nada sobre ele, e as autoridades do período não demonstraram nenhum interesse em investigá-lo. A figura de um padre no processo de Lucia abre brechas para que o autor possa discutir e investigar sobre os debates religiosos e teológicos sobre o infanticídio.

A mãe de Lucia também é interrogada durante o processo, porém a mesma afirma que não sabia da gravidez da filha, assim como suas vizinhas também não o sabiam. Lucia afirmava que sofria de problemas intestinais, o que justificava o aumento de seu ventre. Nota-se aí que Lucia estava "sozinha" como ela mesma afirmou em uma das partes dos autos do processo. Ela não contava com a tutela de uma figura masculina e tampouco fazia parte de uma rede de relações de mulheres que poderiam elucidá-la sobre os mistérios do corpo feminino, como, por exemplo, técnicas abortivas ou constatação de gravidez.

É importante enfatizar que os conhecimentos que se têm hoje sobre o corpo são completamente diferentes dos existentes naquele período. Naquela época, a gravidez era algo misterioso, não eram nítidos e acessíveis os processos de formação do feto e do sexo da criança. E muitas mulheres realmente não sabiam que estavam grávidas até a hora do parto. Não se sabe ao certo se esse seria o caso de Lucia, pois sua mãe afirmou que notando que a filha estava doente a levou para fazer sangria, um dos métodos abortivos existentes naquele período. 
No decorrer do processo judicial, verificou-se que Lucia havia dado a luz a um menino, com todas as unhas em seus dedos e com cabelo na cabeça, um menino bem formado em todas as suas partes, segundo a análise de médicos da época. $\mathrm{O}$ fato de a criança ser do sexo masculino pode colocar um peso a mais no processo de Lucia. Os autos em si não revelam isso, porém Prosperi analisa através de censos da época que o número de registros de nascimento eram muito maiores para meninos que eram mais valorizados, principalmente na cultura popular camponesa, por comporem mais rapidamente a força de trabalho e a partilha de terras. O nascimento de uma menina era muitas vezes um fardo para a família, sendo notória a infelicidade dos pais até mesmo no momento do batismo, que era diferenciado de acordo com o sexo da criança.

Outra questão muito interessante discutida por Adriano Prosperi é a do nome próprio como fio condutor da humanidade. Ele faz o questionamento se alguém sem nome poderia ser um sujeito da história, fazendo essa problematização a partir da análise da figura do recém-nascido que, afinal de contas, mesmo com sua vida breve, sem possuir um nome e muito menos um batismo, modificou por completo a vida de Lucia Cremonini. O nome próprio naquela época não estava associado à individualidade, os nomes eram geralmente de santos, portanto era grande o número de nomes repetidos, o que dificulta o trabalho dos historiadores no ato de procura por dados nos documentos arquivados nos cartórios.

A última parte do livro - talvez a que possua uma maior discussão teológica - aborda o debate sobre o momento em que a alma passa a fazer parte do corpo, além da sentença aplicada à Lucia: o enforcamento público, que funcionava como um ato civilizador, um exemplo do que uma mulher não deveria fazer. O processo de Lucia foi resolvido rapidamente, demorou cerca de um ano até sua condenação, percebe-se durante o andamento que a figura, a personalidade que foi traçada no início dos autos era muito diferente daquela apresentada no final. Primeiramente Lucia foi tida como assassina cruel, que matara seu filho, um crime inominável e capital. Após a sentença de morte por enforcamento, Lucia tem o apoio espiritual da Igreja, que através de seus consoladores, pertencentes à Irmandade de Santa Maria da Morte estiveram ao lado de Lucia para a acompanhar.

Nos relatos dos consoladores Lucia não aparece mais como assassina, e sim como "paciente" ou "aflita". De acordo com as descrições, a jovem se mostrou totalmente resignada, não apresentou nenhum tipo de oposição a sua pena e fez todos os ritos solicitados, dentre eles a confissão, a comunhão, o martírio - mesmo com sede negou-se a beber água - e optou, após muita insistência dos religiosos por uma comida leve e simples. Sua morte foi anunciada a toda a comunidade, foram anexados cartazes e avisos nos mais diversos locais. A execução era um grande acontecimento na comunidade, 
principalmente quando se tratava do enforcamento de uma mulher. A população apareceu em massa e, segundo o autor, percebe-se uma identificação dela com a figura de Lucia. Antes, assassina e merecedora da pena, a jovem agora era vista como resignada quase uma santa por aceitar seu destino, possuir o arrependimento e se converter em uma mulher corajosa perante tal evento. Essa era a imagem de Lucia, presente nos relatos dos consoladores.

Partindo para a questão teológica, Prosperi discute sobre o momento de "entrada" da alma no corpo, sendo esse o mais variado, havendo concepções de que a alma entrava na criança após alguns dias de vida. Dessa forma, o infanticídio era penalizado de forma mais branda, na maioria das vezes pelo pagamento de uma quantia em dinheiro, o que não foi o caso da Lucia. Percebese que a entrada da alma vai sendo cada vez mais precoce. Atualmente a Igreja Católica acredita que a alma já está presente desde o momento da concepção, o que justifica em muitas partes do mundo a criminalização do aborto. Em outros momentos a alma estaria presente na criança a partir do momento em que ela se mexesse no ventre de sua mãe. Dessa maneira, transfere-se a experiência divina do batismo como passo essencial para ter-se alma para uma questão terrena, onde a mãe vive e compartilha essa experiência.

Outra questão discutida por Prosperi é a valorização da alma e do corpo. Como esta discussão ainda é um tema bastante recorrente, isso faz com que o conteúdo do livro seja bastante atual. Afinal, qual deles seria mais importante? Qual deveria ser salvo - o corpo ou a alma? Nota-se, no século XVIII, que a alma era mais importante, pois o corpo, o da mulher no caso, já estava salvo, batizado, portanto uma nova alma tinha mais importância. $\mathrm{Na}$ atualidade, ainda existem discussões polêmicas sobre o corpo feminino. O debate ainda circula em torno destas perguntas: em que casos uma mulher pode fazer um aborto? Quais são os valores morais e religiosos que recriminam tal ato? Qual o poder da mulher sobre seu próprio corpo? Questões salutares que percorreram o contexto de Lucia Cremonini no século XVIII, mas que ainda hoje estão presentes em nossa sociedade. Portanto, isso só vem ratificar o quanto, sob certos aspectos, o ato, o processo judicial, o comportamento dos atores sociais analisados por Prosperi são atuais, embora mais de dois séculos nos separem do caso de Lucia.

O livro de Prosperi é um grande exemplo de erudição, da possibilidade de se fazer uma história que parte do micro, mas que não se desvirtua dos múltiplos contextos que ultrapassam a cidade de Bolonha, eles vão além, tanto geograficamente - quando trata de casos de infanticídio cometidos em outras cidades italianas - ou quando discute questões filosóficas relacionadas ao corpo, a alma e a criminalização do aborto. O autor utiliza diversas fontes como autos de processos judiciais, registros paroquiais de nascimento, documentos da Igreja que abordam questões sobre o aborto e infanticídio, informações sobre 
os saberes médicos de outras épocas, dentre outros. $\mathrm{O}$ autor problematiza as fontes, mas não abre mão da imaginação histórica bem fundamentada para ligar e dar sentido aos fragmentos documentais mostrando um elevado nível de pesquisa documental e um alto nível de erudição na leitura e no tratamento das fontes.

Resenha recebida em outubro de 2011. Aceita em março de 2012. 